\title{
The Effect of Shoe Sizing System on South Indian Ladies
}

\author{
Efrem Eyasu Chute \\ Footwear science and Engineering \\ Anna University \\ Chennai, India
}

\begin{abstract}
One of the obvious distinctions within comfortable and uncomfortable shoes is based on the fit preferences in the different regions of ladies' shoes. Fourth-three young women in the age interval of 16-21 participated in the study. Each participant is asked the experience they have been experiencing as young women regarding the comfort of footwear in written form. And also, each of them went under a threedimensional foot scanning process to make an accurate guess of discomfort. This paper grants an effective overview of the effect of shoe fitting on the customer during the long-term usage of the product.
\end{abstract}

Keywords-Fitting; sizing system; foot pain; footscanner

\section{INTRODUCTION}

A footwear size is an implication of the fitting measurement of a shoe. On long term usage of footwear which does not fit properly can be harsh toward the healthiness of our feet and even for full body. Predicaments by our foot can bring severe health conditions such as swelling, soreness, inflammation, diabetes, nerve, and blood circulation dysfunctions.

Footwear can be defined as an outer covering for the foot, usually of leather with a stiff or thick sole and heel, and generally (distinguishing it from a boot) reaching no higher than the ankle.

There are numerous different shoe-size methods adopted globally. The most common is the customary which for men's shoes is one size shorter than the UK equivalent, making a men's 13 in the US the same size as a men's 12 in the UK. In the Continental European system, the shoe size is the length of the last, expressed in Paris points, for both sexes and for adults and children alike. The Mondopoint shoe length system is widely used in the sports industry to size athletic shoes, ski/skate boots, and pointe ballet shoes; it was also adopted as the primary shoe sizing system In USSR, Rusia, GDR, China, Japan/Taiwan/South Koria and as an optional system in the United Kingdom, India, Mexico, and European countries. NATO and other military services also use the Mondopoint system.

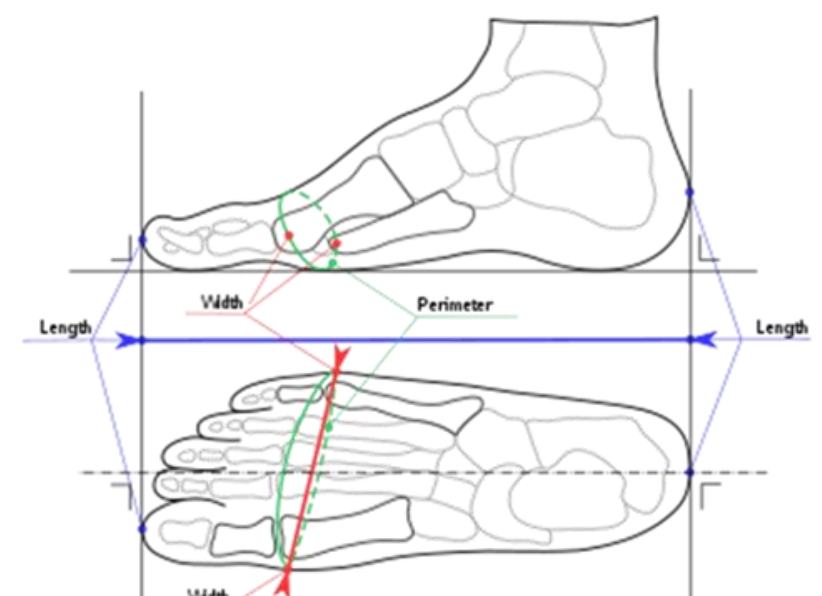

Figure 1. Measurement of foot length, width and perimeter (circumference) as defined in the Mondopoint standard

Next to fashion, shoe fitness is an important selection criterion. To acquire consumer foot information, the shoemaker should have a foot size information system. Such a system should collect consumer foot data for further analysis such as shoe last design and population distribution as well as for communication with customers. When the foot-shoe "tightness" exceeds a certain threshold, discomfort, or pain results.
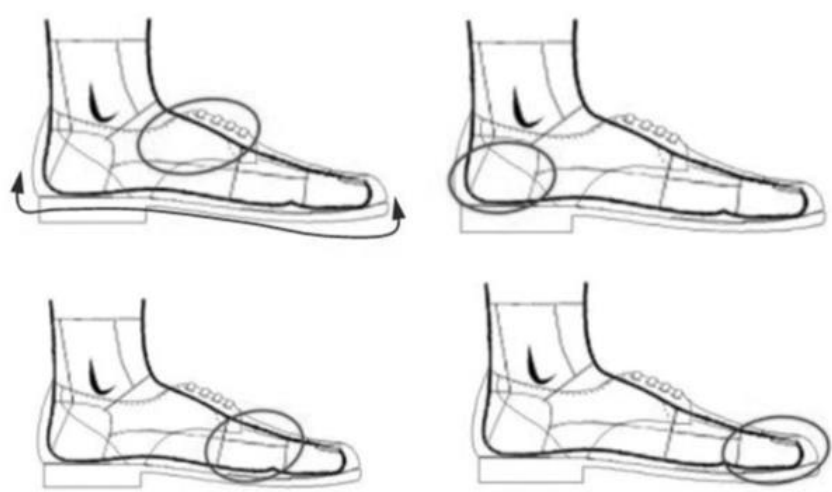

Figure 2. Shoe areas analyzed during personal fit preference tests

Humans have used footwear for approximately 30,000 years. Although originally worn as a protective covering for the foot, modern footwear is designed to fulfill a range of purposes, the accomplishment of which is judged by three criteria: form, function, and fit. Fit pertains to how footwear 
can accommodate the morphology of the foot. Footwear fitting is acknowledged as being vitally important as in most cases fit governs function. This means that footwear cannot fulfill its intended purpose if it does not fit the foot correctly. Furthermore, it has been suggested that incorrectly fitted footwear is a major contributor to the development of structural foot disorders, such as hallux valgus and lesser toe deformity as well as skin lesions, such as corns and calluses.

\section{APPROACH}

\section{A. Sample determination}

Sample size determination is the act of determining the number of observations or replicates to include in an analytical representation. Sample size is a group of subjects that are chosen from the overall population and is viewed as a representative of the actual population for that specific study. In application, the sample size used in research is habitually decided depend on the cost, time, or suitability of gathering the data, and the demand concerning it to contribute satisfactory statistical stamina.

More massive sample sizes decrease sampling error just at a decreasing scale. Numerous statistical formulas are available for determining sample size. There are numerous approaches, incorporating many different formulas, for calculating the sample size for certain data.

$$
n=\frac{\mathrm{p}(100-\mathrm{p}) \mathrm{z}^{2}}{E^{2}}
$$

$\mathrm{n}$ - is the required sample size

$\mathrm{P}$ - is the percentage occurrence of a state or condition

$E$ - is the percentage maximum error required

$\mathrm{Z}$ - is the value corresponding to level of confidence required Total population of Tamil Nadu is $=36,009,055$ (Census of India)

Female in the age interval of $16-21$ is $9.7 \%$

$$
\begin{gathered}
\text { Confidence }=95 \% \quad \mathbf{p}=0.5 \quad \text { Error }=0.14 \\
n=36,009,055 \times 9.7 \%=3,492,878
\end{gathered}
$$

Alpha divided by 2: $\quad \frac{1-.95}{2}=0.025$

\section{Z} score $=$ Norms.slnv $(1-0.0025)=1.96$

$$
\begin{aligned}
& \text { Sample size }=\frac{\frac{Z^{2} \cdot P(1-P)}{e^{2}}}{1+\left(\frac{Z^{2} \cdot P(1-P)}{e^{2} \cdot N}\right)} \\
& \frac{\frac{1.96^{2} * 0.5(1-0.5)}{0.155^{2}}}{1+\left(\frac{1.96^{2} * 0.5[1-0.5)}{0.155^{2} * 8.492 .878}\right)} \approx 40
\end{aligned}
$$

\section{B. Data collection and analysis}

While the present fitting system is custom-built based on the European footwear market; the last has a fitting downside, that results in affect locomotion of Tamilian customers. Throughout the project section, the foot of population representatives from Tamil Nadu is scanned using a 3D foot scanning machine. The girth size of the Indian foot is assumed to be wider. due to the weather and customary outfit (Saree) the ladies prefer to wear open footwear. This typical usage of open footwear brings wider ball girth compared to the European fitting system.
Demographically the sample of the population is $16-21$ years aged female who came from different parts of Tamil Nadu. Data has been collected from 55 subjects in total.

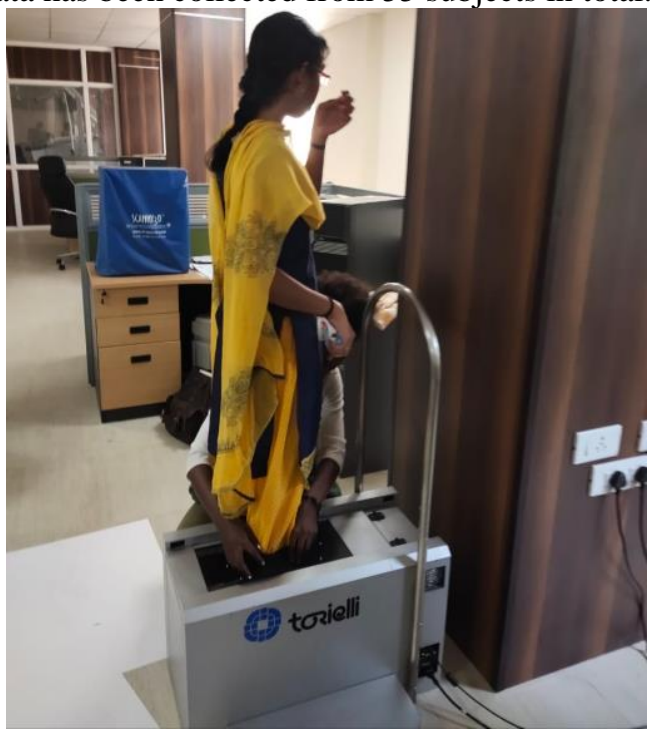

Figure 3Data collection

\begin{tabular}{|l|l|l|l|}
\multicolumn{5}{|c}{ Table 1. Fitting percentage } \\
\hline Fitting & Frequency & Percent & Cumulative Percent \\
\hline E & 4 & 9.1 & 9.1 \\
\hline F & 10 & 22.7 & 31.8 \\
\hline G & 5 & 11.4 & 43.2 \\
\hline H & 10 & 22.7 & 65.9 \\
\hline SE & 2 & 4.5 & 70.5 \\
\hline XH & 6 & 13.6 & 84.1 \\
\hline XXH & 7 & 15.9 & 100.0 \\
\hline Total & 44 & 100.0 & \\
\hline
\end{tabular}

\begin{tabular}{|l|l|l|l|l|l|}
\multicolumn{9}{|c|}{ Table 2. Priority table } \\
\hline & Priority I & Priority II & $\begin{array}{l}\text { Priority } \\
\text { III }\end{array}$ & $\begin{array}{l}\text { Priority } \\
\text { IV }\end{array}$ & Priority V \\
\hline Sandal & 22 & 7 & 7 & 3 & 4 \\
\hline Leather & 3 & 6 & 17 & 13 & 5 \\
\hline Court & 12 & 17 & 7 & 8 & 1 \\
\hline Sports & 2 & 8 & 13 & 17 & 4 \\
\hline High heel & 5 & 6 & 1 & 3 & 29 \\
\hline
\end{tabular}

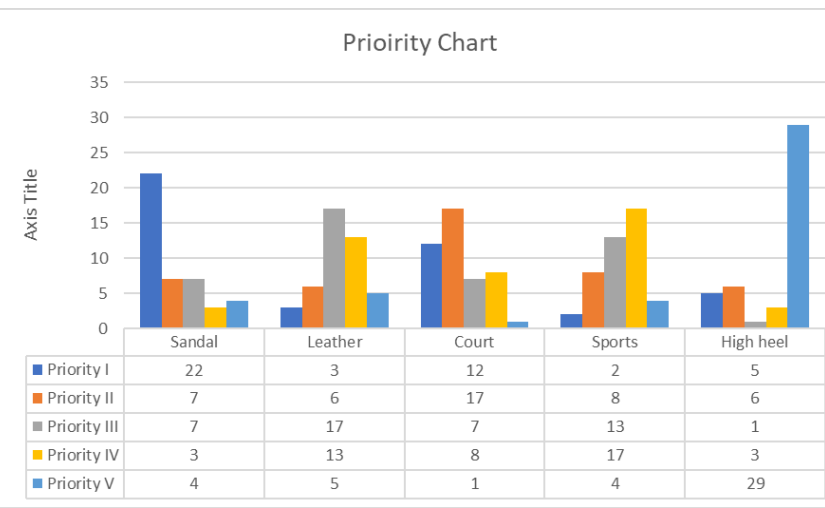

Figure 4. Priority Chart 


\begin{tabular}{|l|l|l|l|}
\multicolumn{4}{c}{} \\
\multicolumn{1}{|c|}{ TABLE 3. OWNED VS PREFERRED } \\
\hline & $\begin{array}{l}\text { Preferred } \\
\text { percentage }\end{array}$ & $\begin{array}{l}\text { Owned } \\
\text { percentage }\end{array}$ & Deference \\
\hline Sandal & 26 & 52 & -26 \\
\hline Leather & 18 & 12 & 6 \\
\hline Court & 25 & 21 & 4 \\
\hline Sports & 18 & 13 & 5 \\
\hline High heel & 13 & 2 & 11 \\
\hline
\end{tabular}

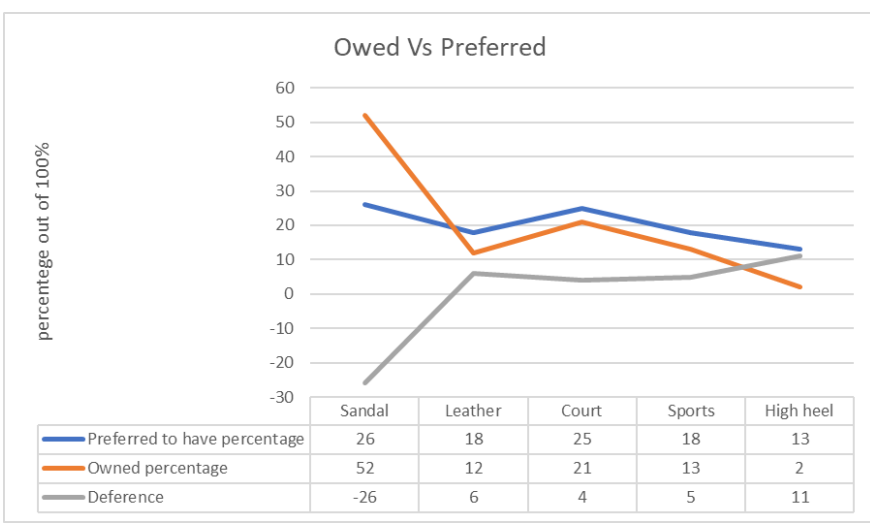

Figure 5. Owned vs Preferred chart

Table 4. Foot pain registered from the subjects

\begin{tabular}{|c|l|l|}
\hline No. & Types of foot pain & No of subjects \\
\hline 1. & Toe region & 7 \\
\hline 2. & Ankle region & 6 \\
\hline 3. & Metatarsal region & 2 \\
\hline 4. & Nail region & 1 \\
\hline 5. & Sore feet & 1 \\
\hline
\end{tabular}

\section{CONCLUSION}

Existing standard for sizing system (Indian Standard Specification for Sizes and Fitting of Footwear" is ISO standard used by the footwear manufacturer as reference. Based on collected data from the subjects implies deviation.16 subjects out of 55 total has foot pain which is about $30 \%$. The deviation of fitting on the standard affected the health of footwear customers. Also, 52\% of population footwear is
sandal/Chappal. This makes the form of foot difficult for generating standard.

\section{ACKNOWLEDGMENT}

Author thanks CLRI-CSRI for permitting access to their facilities such as 3D foot scanner and system for landmark point editing of a three-dimensional collected data. Also Dr. J. Raghava Rao (Chief scientist, Head of the Department, Department of Leather Technology, Anna University-CLRI, Chennai), Mr. Md Sadiq (Chief Scientist \& Head SPDCCLRI) and Dr. K. Krishnaraj (Senior principal scientist, SPDC -CLRI) and Dr. D. SURESH KUMAR (Senior principal scientist, SPDC -CLRI)

\section{REFERENCES}

[1] Michael W. Whittle, "Gait Analysis: an introduction", Third Edition, Chattanooga, USA

[2] Beatriz Nácher, Juan Carlos González, Sandra Alemany "A Footwear Fit Classification Model Based on Anthropomeric Data" Article · July 2006

[3] Luximon, Ameersing and Yan Luximon. "Shoe-last design innovation for better shoe fitting." Comput. Ind. 60 (2009): 621-628.

[4] Luximon, Ameersing and Yan Luximon. "Shoe-last design innovation for better shoe fitting." Comput. Ind. 60 (2009): 621-628.

[5] Bessie Hurst, Helen Brathwaite, Andrew Greenhalgh \& Nachiappan Chockalingam, Medical-grade footwear: the impact of fit and comfort, Journal of Foot and Ankle Research, Published: 05 January 2017.

[6] César Calvo-Lobo, Ana Ramos García, Marta Elena Losa Iglesias, Daniel LópezLópez, David Rodríguez-Sanz, Carlos Romero-Morales, and Ricardo Becerro-deBengoa-Vallejo, The Relationship between Shoe Fitting and Foot Health of Persons with Down Syndrome: A Case Control Study, Published online 2018 May 14.

[7] Ales Jurca, Jure Zabkar, Analysis of 1 Million 3D Foot Scans from North America, Europe, Asia and Australia, Conference Paper. October 2018

[8] Ameersing Luximon, Dynamic footwear fit model similar to NIOSH lifting equation, 6th International Conference on Applied Human Factors and Ergonomics (AHFE 2015) and the Affiliated Conferences, AHFE 2015

[9] "INFOOT Landmarks and Measurements English" http://www.iwl.jp/en/content/infoot.html

[10] Determining Sample Size; How to Calculate Survey Sample Size, Article · February 2017

[11] A qualitative study on the comfort and fit of ladies' dress shoes, The Hong Kong University of Science and Technology, November 2007

Efrem Eyasu

B.Sc. in Manufacturing Engineering

MTech in Footwear science and Engineering, Anna

University, Chennai, India.

Technologist at Leather Industry Development Institute (Ethiopia)

Guest Lecture at Addis Ababa Science and Technology 